\title{
Arthropods as Vertebrate Predators: A Review of Global Patterns
}

\author{
Jose Valdez \\ Department of Bioscience - Kalø, Aarhus University, Grenåvej 14, 8410, Rønde, \\ Denmark \\ Correspondence: jose.valdez@bios.au.dk
}

\begin{abstract}
Arthropod predators preying on vertebrates is generally overlooked in ecological studies, as it is not typically observed in nature and generally considered a rare event. This is likely due to the cryptic nature of these predatory events, the relatively small size of arthropods, and the difficulty in collating published data which is scattered throughout the literature. Although arthropods are known to readily hunt and consume vertebrates, very little is known about these predatory events. In this study, a systematic literature review was conducted to provide a conceptual framework, identify global patterns, and create a searchable database of arthropod preying on vertebrates. This study represents the largest global assessment of arthropod predators and vertebrate prey with over a thousand recorded observations collated from over 80 countries across every continent except Antarctica, where no arthropod predator exists. Arthropod predators were represented by six classes (insects, arachnids, centipedes, and crustaceans: Malacostraca, Ostracoda, Hexanauplia) and over 80 families. Vertebrate prey were represented by five classes (birds, mammals, reptiles, amphibians, fish) and 160 families. The most common prey were frogs consisting of over a third of all observations. The most commonly preyed reptiles were nearly all lizards, half of mammal prey were bats, nearly a third of fish were Cypriniformes, and half of bird prey were passerines. Spiders represented over half of all predatory events found and were the main predator for all vertebrates except birds, which were preyed mostly upon praying mantises. However, prey varied between spider families. For insects, true bugs (Hemiptera) and beetles preyed mostly on amphibians while the aquatic Odonata larvae preyed on amphibians and fish. Decapod predators were observed preying equally between reptiles, birds, and amphibians; with centipedes preying mainly on reptiles and mammals. Predation was mostly recorded from the Americas and Australia, with countries and regions varying between predator and prey groups.
\end{abstract}


This study demonstrates that arthropods are indeed an overlooked predator of vertebrates. Recognizing and quantifying these predator-prey interactions is vital for identifying patterns and the potential impact of these relationships on shaping vertebrate populations and communities. Understanding the possible threat of arthropod predators may be especially important to improve the success of conservation efforts by accounting for predators which may currently be overlooked.

Keywords: predator-prey; insects; arthropods; entomology; herpetology; species interactions; predation

\section{Introduction}

Predator-prey interactions are a main driver of natural selection, population dynamics, food web structure, community assemblages, and ecosystem function (Darwin, 1859, Gross, 1978, Portalier et al., 2019). As top-down regulators, predators shape ecological communities, having far-reaching effects on environmental processes, ecosystem resilience, and biodiversity (Estes et al., 2011, Sergio et al., 2006, Terborgh and Estes, 2013). This has been demonstrated with the reintroduction of large apex vertebrate predators into their former habitats, which is well known to have substantial effects on ecosystem recovery and restoration of both plants and animals (Beschta and Ripple, 2009, Sergio et al., 2005, Sergio et al., 2006, Ripple and Beschta, 2012). Even relatively small predators can have a top-down control within the food webs of many ecosystems (Moran and Hurd, 1997, Moran et al., 1996), with arthropod predators commonly used as biological control of pests in agriculture and forestry (Kenis et al., 2017). Arthropod predators can also have a relatively large ecological impact, with spiders alone estimated to consume up to 400-800 million metric tons of insect prey annually (Nyffeler and Birkhofer, 2017). However, although arthropods are also known to occasionally consume vertebrate prey, predation on vertebrates has not attracted much attention and remains relatively understudied (Nordberg et al., 2018).

Recognizing the predator-prey interactions that exist between arthropods and their vertebrate prey is vital for understanding how arthropods can shape vertebrate populations and 
communities. This could be especially important for threatened vertebrate populations, with recent evidence demonstrating that arthropod predators have the capacity to negatively impact or hinder conservation efforts of vertebrates such as fish (Stanton et al., 2019) and amphibians (Valdez, 2019). While some studies have shown arthropods may have a large impact on vertebrates in experimental settings (Kopp et al., 2006, Wizen and Gasith, 2011, Pearman, 1995, Nordberg et al., 2018), very few studies have examined arthropod predation under natural conditions, resulting in these predation events being considered rare in nature. Although one can quickly find millions of videos, photos, and newspaper accounts online of arthropods preying on vertebrates, they are only occasionally documented in scientific literature, with most published articles scattered as single individual observations and appearing in the literature as natural history notes. Despite literature searches becoming much easier with the internet, these articles are still difficult to find, resulting in studies incorrectly stating there are only a few cases recorded (Bastos et al., 1994, Bernarde et al., 1999) or that they are the first published accounts of such predatory events (Hibbitts, 1992). The complications in finding these published accounts will only be further compounded as natural history science continues to decline (Tewksbury et al., 2014). Furthermore, as this information remains scattered throughout the literature it reiterates the presumed rarity of arthropod predation on vertebrates and makes it increasingly difficult to identify patterns and the potential impact of these trophic relationships.

Although literature reviews have been undertaken to recognize the importance of arthropod predators on vertebrates, they have mostly been conducted on specific prey (Toledo, 2005), particular predator-prey relationships (e.g. praying mantis as fish predators (Nyffeler et al., 2017b), spiders preying on mammals (Nyffeler and Vetter, 2018), bats (Nyffeler and Knörnschild, 2013), fish (Nyffeler and Pusey, 2014), and squamates (O'Shea and Kelly, 2017)), with many others further focusing exclusively on specific regions (e.g. neotropical spiders preying on amphibians (Menin et al., 2005), frogs and lizards as prey of Greater Antillean arachnids (de Armas, 2001)). Moreover, these studies typically include predation events in laboratory settings which may or may not be representative of what occurs in nature. The only comprehensive global review of arthropod predation was conducted four decades ago by Mccormick and Polis (1982), where they identified arthropods as an important and overlooked predator of vertebrates. In their major review, they detailed a lack of quantitative data and emphasized the importance of studying arthropod predation in future ecological research. However, their recommendation has since been mostly 
ignored with very little progress having been made and the importance of these trophic relationships remaining largely unclear.

For this study, a global analysis of arthropod preying on vertebrates was undertaken on the available published scientific literature. This systemic literature review was conducted to provide a conceptual framework, identify global patterns, and create a searchable database of arthropod predators and their vertebrate prey.

\section{Methods}

An extensive literature search of vertebrate predation by arthropods was undertaken between November and December 2019. Scientific articles, books, theses, dissertations, technical reports, and conference proceedings were searched using Google Scholar, Scopus, and Web of Science. Literature was also found indirectly by examining references cited by the original article, articles which cited the original, as well as articles recommended by the database. Many secondary citations were from Herpetological Review, which was not indexed in any scientific database. Therefore, a comprehensive review of their archive from 1967 to 2019 was also included. The class, order, and family of the prey and predator, as well as the country where the event occurred was recorded, if available. Predatory events were included only if they met the following conditions: (1) an arthropod predator was directly observed attacking and then consuming or attempting to consume a vertebrate, (2) if the prey was not alive it was assumed by the authors to have been caused by the predation event, (3) the event occurred in the field or a natural (not laboratory) experiment, and (4) and the prey was post-hatching (larvae, juveniles, adults).

\section{Results}

A total of 1,282 arthropod predation events on vertebrates were found in 80 countries (Appendix). Arthropod predators documented in the literature were from six classes, 22 orders, and 82 families (Figure 1a); The most common class of predators were arachnids (Arachnida), accounting for $56.74 \%$ of all observed predation events, followed by insects (Insecta) with 32.6\% . Nearly all arachnid observations (93.09\%) were spiders (Araneae); insects were made up of mostly true bugs (Hemiptera) (31.01\%), mantises (Mantidae) (21.63\%), and beetles (Coleoptera) (20.67\%); while Malacostraca crustaceans were nearly all decapods (Decapoda) (96.7\%) (Figure 
1a). The most diverse orders of predators containing the most families were spiders and decapods (Figure 1a).

Vertebrates were observed from five classes, 77 orders, and 160 families (Figure 1b). The most common vertebrate class was amphibians (Amphibia) with 39.34\% of all observations, followed by reptiles (Reptilia) with $22.1 \%$. For amphibians, $94.82 \%$ of observations were frogs (Anura), mainly those in the Hylidae and Leoptodactylidae families (Figure 1b). The most commonly preyed upon reptiles (Reptilia) were lizards (Squamata) (89.01\%), nearly half of birds (Aves) were passerines (Passeriformes) (47.29\%), half of mammals were bats (Chiroptera) $(52.42 \%)$, while nearly a third of fish (Actinopterygii) were from the Cypriniformes order (28.48\%) (Figure 1b). Frogs contained the most prey families, followed by passerines and lizards (Figure $1 b)$.

Arachnids, particularly spiders, were by far the main predator for all vertebrates (Figure 4a, c-e), except for birds which were preyed upon by insects, mainly praying mantises and ants (Figure 4b). Although spiders were the most common predator, their prey varied between spider families, with Ctenidae preying mostly on frogs, Theridiidae preying on lizards and rodents (Rodentia), Pisauridae mostly on amphibians and fish, and Araneidae on birds and bats (Figure 2a). For insects, the Hemiptera and Coleoptera orders preyed mostly on amphibians, mantises mostly on birds, and Odonata on amphibians and fish (Figure 2b). Decapod predators were observed preying equally between reptiles, birds, and amphibians, with centipedes (Chilopoda) preying mainly on reptiles and mammals (Figure 3b). Predation by spiders and other arthropods was documented mainly from the United States, Brazil, and Australia; with insects mainly from the United States, Brazil, and other South American countries (Figure 4). Birds and mammals were mainly documented from the United States and Australia; amphibians were from Brazil and the Americas; reptiles mainly from the United States, Australia, and Brazil; and fish were preyed upon mostly from North America and Australia (Figure 5). 

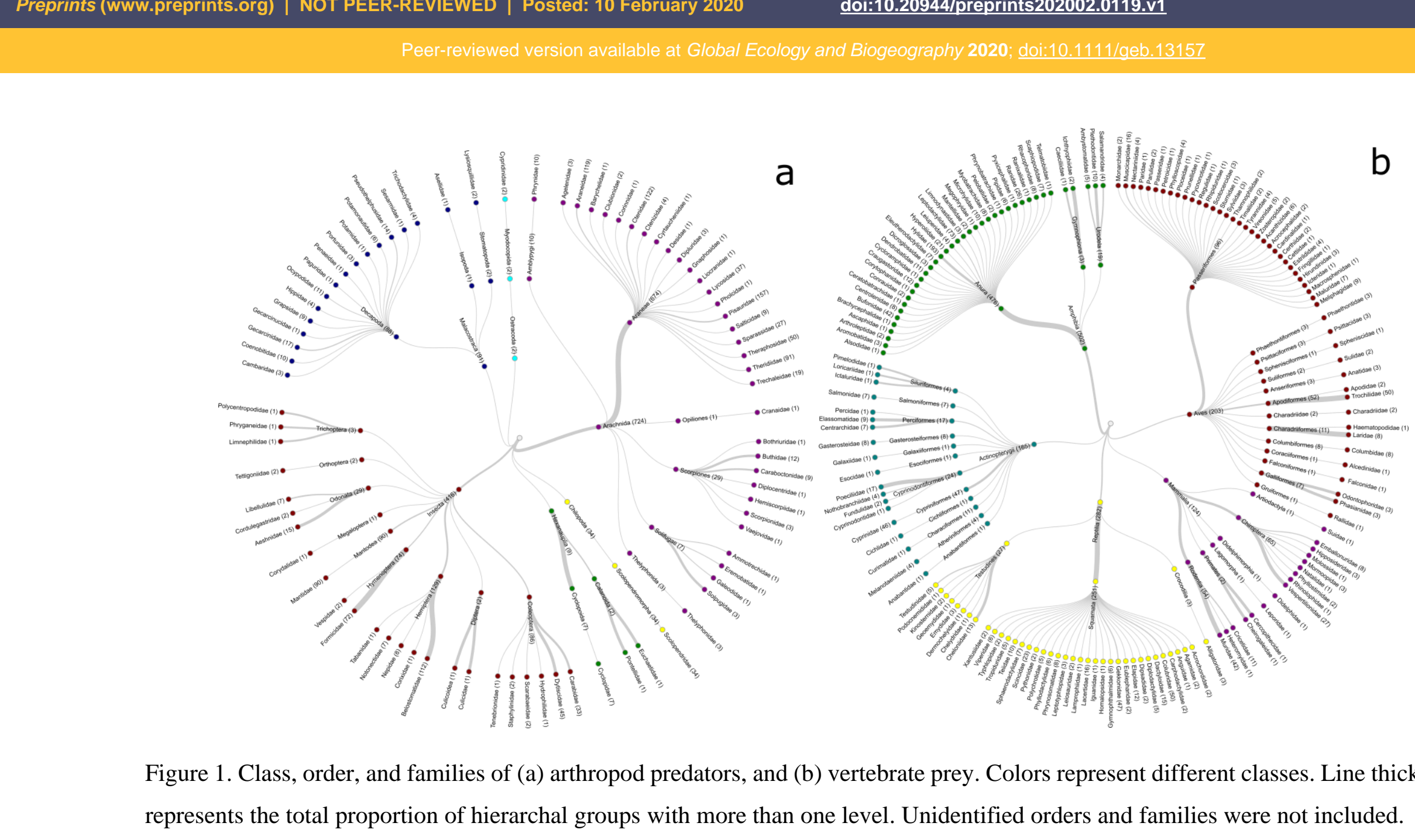

Figure 1. Class, order, and families of (a) arthropod predators, and (b) vertebrate prey. Colors represent different classes. Line thickness represents the total proportion of hierarchal groups with more than one level. Unidentified orders and families were not included.

\section{b}

\footnotetext{
reprent he total proportion of hierarchal groups with me tha one level. Unidied ordess and failies were not included.
} 

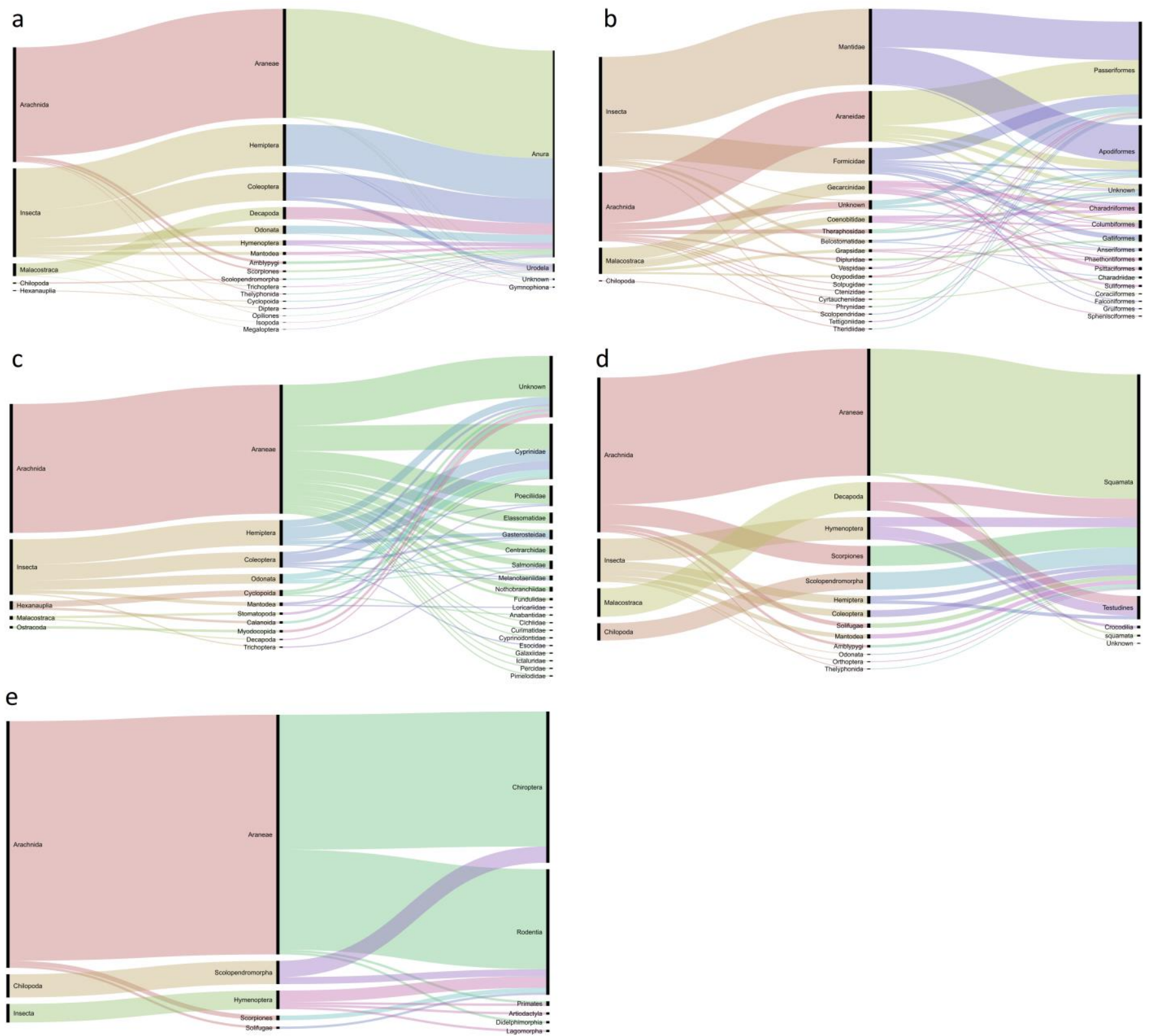

Figure 2. Arthropods predators (by class and order) and their vertebrate prey (by order): (a) amphibians, (b) birds, (c) fish, (d) lizards, and (e) mammals by the total number of predatory events documented in the scientific literature. 

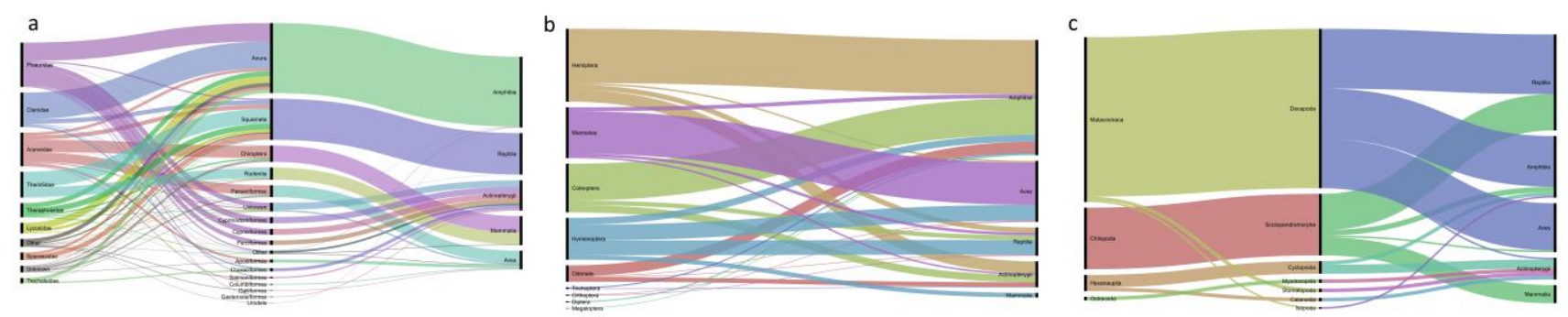

Figure 4. Orders of (a) Arachnida, (b) Insecta, and (c) other arthropods, along with their vertebrate prey by the total number of events documented in the scientific literature. Prey order was not included in (b) and (c) for clarity. 


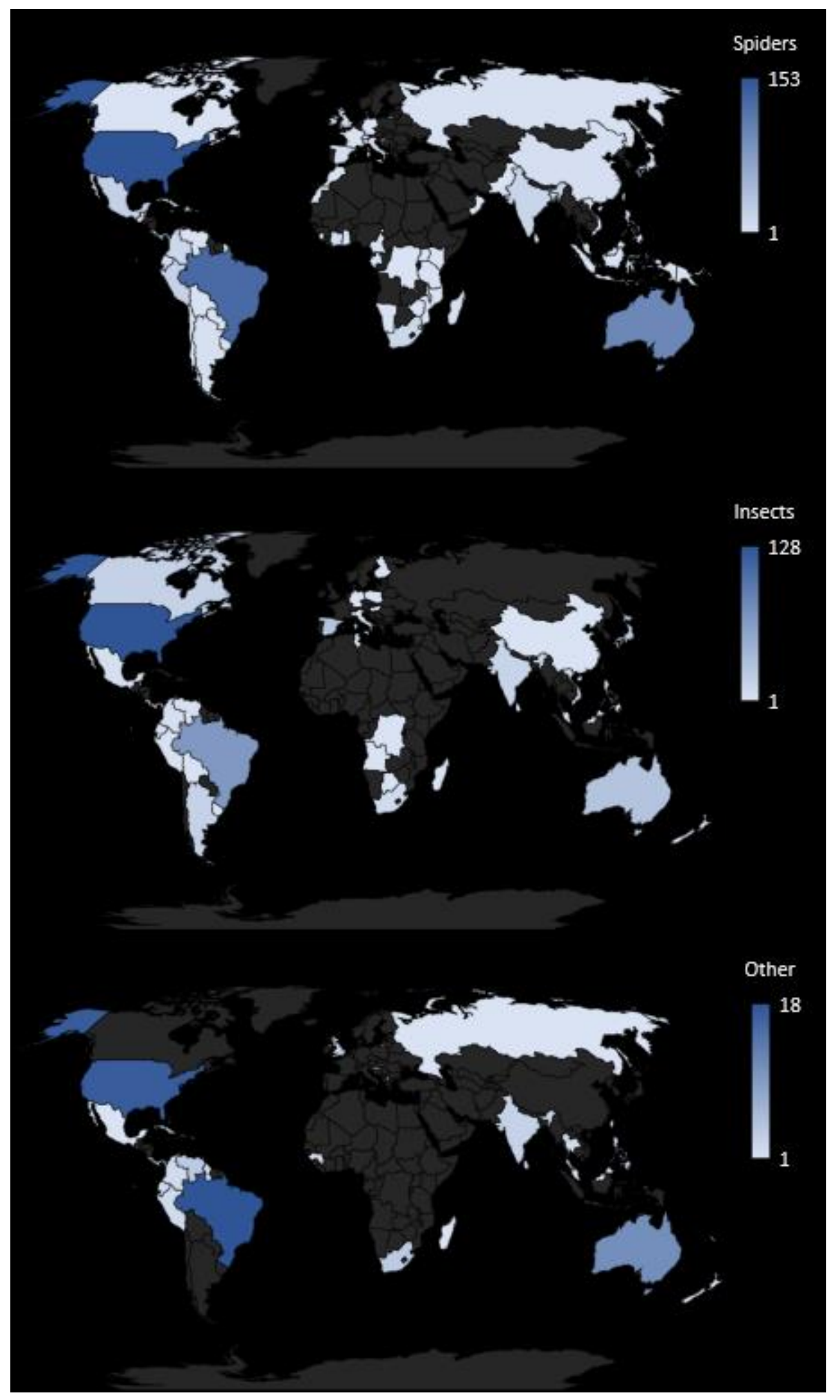

Figure 4. Arthropod predation on vertebrates by predator class around the world. Colors show the count of documented predation events per country. 


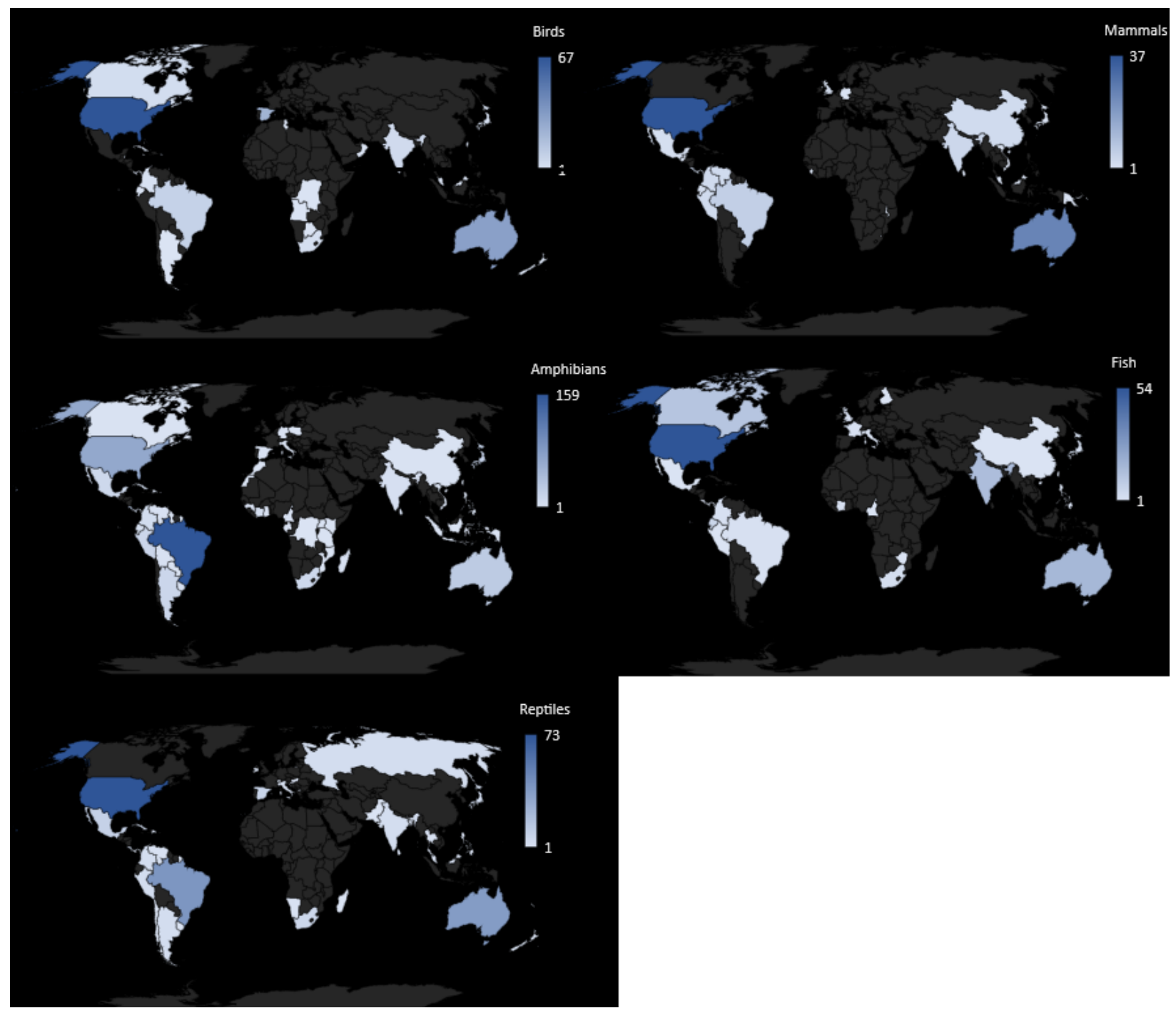

Figure 5. Arthropod predation on vertebrates by prey class around the world. Colors show the count of predation events per country.

\section{Discussion}

This study represents the largest global assessment of arthropod predation on vertebrate prey with over a thousand predation events found in the scientific literature. Observations were recorded from every continent (except Antarctica, where no predatory arthropod exists) and over 80 countries but mostly concentrated in the United States, Brazil, and Australia. As arthropod predators are found all over the world, these findings likely represent a bias due to ecological studies heavily skewed towards these regions. Although arthropods are more diverse than vertebrates, there were over 3 times more vertebrate orders and twice the number of vertebrate 
families than arthropods. This may be because most of the documented observations are based on research which tends to be heavily skewed towards vertebrates (e.g., many reports were from herpetological and ornithological journals). Besides being less charismatic as a research subject, arthropods are also generally more cryptic due to their smaller size and difficult-to-observe predatory behaviors which typically occur at night, within forests, or underwater; also biasing the results more toward vertebrate prey.

The largest predator group was spiders, which were the major predator for all vertebrate classes except birds. This is unsurprising since the total standing biomass of the global spider community is nearly 25 million metric tons, preying on a similar order of magnitude of prey as all the whales in the world's oceans (Nyffeler and Birkhofer, 2017). However, these results may also be simply due to spiders being the subject of many review articles (Babangenge et al., 2019, Nyffeler and Vetter, 2018, Nyffeler et al., 2017a, Nyffeler and Pusey, 2014, Nyffeler and Knörnschild, 2013, Maffei et al., 2010, Menin et al., 2005, Steehouder, 1992, Blondheim and Werner, 1989, Morris, 1963, Butler and Main, 1959, Neill, 1948). Nevertheless, spiders possess strong fangs capable of piercing vertebrate skin and injecting them with neurotoxins, many specific to the nervous system of vertebrates (Garb and Hayashi, 2013, Gregio et al., 1999). They also have a diversity of tactics such as active hunting, sit-and-wait ambush, and for many, the production of webs which can entangle many small animals unlucky enough to encounter them. These webs are so strong, birds are consistently found entangled in them, with many reviews published regarding this phenomenon (Kasambe et al., 2010, Brooks, 2012, Abbott, 1931). Another major difference between spiders and other arthropods is that spiders can grow much larger than most arthropods, including very large species such as the goliath bird eater (Theraphosa blondi) in the Theraphosidae family. Their size and the ease of discovering prey caught on their spider webs also makes it much easier to observe predation events compared to other arthropods.

Spiders were found to differentiate among their target prey based on their predatory strategies. Wandering spiders (Ctenidae) are nocturnal, venomous, ambush hunters that preyed mostly on frogs, which would be easy targets for these spiders due to their similar nocturnal behaviors and sedentary lifestyle. Tangle-web spiders (Theridiidae) are known for their web building and venomous bite, including those from black widows (Latrodectus). This group of spiders are the most common arthropod found in human dwellings and may explain why the most 
common prey were lizards and rodents, other common house inhabitants (Leong et al., 2017). Nursery web spiders (Pisauridae), which include fishing spiders, unsurprisingly preyed most on the aquatic animal groups of amphibians and fish. Lastly, orb-weaver spiders (Araneidae) often feed on birds and bats, which they would commonly encounter due to their occurrence in gardens, fields, and forests. Furthermore, orb-weavers are known for their strong and very large webs (including the largest web and longest bridge line ever recorded) which makes them well-suited to capture these large flying prey (Kuntner and Agnarsson, 2010).

Another common predator were insects, with different orders also preying on different vertebrate groups. The largest was Hemiptera which were mostly giant water bugs in the Belastomidae family. These large, aquatic predators are known to be able to consume everything from turtles to fish due to their large mandibles (Ohba, 2019). In this study, they mostly preyed on aquatic vertebrates such as amphibians and fish. Odonata larvae are another large aquatic predator that was found to mostly consume amphibians and fish. As the only major flying insect predator, praying mantises were mostly observed preying on birds. Mantises can not only get to bird nests and eat fledglings through their ability to fly but are also well known to capture small birds, especially hummingbirds in mid-air (Hildebrand, 1949, Murray, 1958, Fisher Jr, 1994, Lorenz, 2007), and are the only known insect to impale their prey with its legs (Rivera and Callohuari, 2019). Decapod crustaceans, which mostly consisted of crabs, didn't exhibit any preference and were equally found to prey on reptiles, amphibians, and birds alike; which may have to do with their wide range of terrestrial, arboreal, and aquatic lifestyles. Another common predator was scorpions, an arachnid with large venomous fangs and aggressive hunting, which mainly consumed reptiles and mammals which are also found in similar forest environments.

The largest group of vertebrate prey were amphibians, specifically frogs. Frogs are so wellknown to be preyed upon by such a wide range of predators, including carnivorous plants, that it has been stated that 'practically anything will eat an amphibian' (Duellman and Trueb, 1994). This may be because frogs are especially vulnerable due to their soft easily penetrable skin and lack many of the defenses against predation seen in other vertebrates. For example, they can't fly like birds or bats, can't quickly run away like lizards and mammals, and don't have teeth, nails, or other defense mechanisms to adequately protect themselves. Compounding this vulnerability, frogs typically have both aquatic and life stages, with many species also arboreal. This increases the 
types and number of predators they are likely to encounter and makes them vulnerable to aquatic, terrestrial, and arboreal predation. These various predators include diving beetles that are known to feast on tadpoles (Gould et al., 2019), water bugs that feast on metamorphs and juveniles (Fadel et al., 2019), and spiders which may be the most important arthropod predator of adult frogs (Toledo, 2005). The Hylidae group of tree frogs have all these qualities which may explain why they may have been the largest order preyed upon. This tendency for frogs to get eaten explains their typical r-selected strategy, with very large clutch sizes compared to other vertebrate groups, which can sometimes number in the tens of thousands (Lever, 2001).

Another large prey group was reptiles, with the largest families being geckos, skinks, and snakes which were eaten by a diverse group of predators. Although they have various defense mechanisms, groups such as geckos are easy targets due to their relatively small size and lack of strong teeth or nails, compared to other lizards. Although snakes and skinks are better equipped at protecting themselves given their speed, venoms, and fangs, they may still be subdued by the neurotoxins of many of these arthropods, especially scorpions where up to ten percent of their diet are snakes (Greene, 1997). Moreover, juveniles and hatchlings are especially vulnerable due to their smaller sizes. The third-largest prey groups were birds, particularly passerines and hummingbirds which contain small bird species that are more easily caught and consumed by arthropod predators. Hummingbirds include the smallest bird species and were mostly preyed upon by mantises, while spiders had an affinity for passerine birds. For fish, Cyprinidae was the most common family preyed upon, which is unsurprising as they are not only the most diverse fish family but the most diverse vertebrate family in the world (Froese and D., 2019). Lastly, the most common mammals were bats and rodents, both of which were preyed upon mainly by spiders and centipedes. Although bats can fly, they are easy targets as they roost, with their particularly vulnerable young. Juvenile rodents such as rats and mice are also completely helpless as young, requiring extensive parental care, which would make them particularly vulnerable to predation if separated from their parents. However, adults can also easily be taken down by large spiders and centipedes once they have been incapacitated after being injected with venom (Gregio et al., 1999, Ménez et al., 1990).

Although this study is a systematic review of arthropod preying on vertebrates, it only represents the most common predatory events reported in the scientific literature, which may be 
more diverse in nature and less biased towards certain groups. Caution is advised when interpreting these results since the frequency or patterns recorded in the literature may not be representative of what occurs in nature, especially since some arthropod predators and predatory events may be more cryptic and much harder to observe than others, making these interactions easy to miss. Nevertheless, these findings provide a good basis for future research to recognize where possible gaps remain. Despite the large number of observations, the results indicate that these predatory events are almost still certainly underestimated. A simple google search results in millions of webpages on a wide range of arthropod predation on vertebrates, demonstrating how common these predatory-prey interactions really are. Moreover, their impacts on vertebrate populations is much greater than reported here, since this study didn't include egg predation, the most vulnerable time for all egg-laying vertebrates. Studies have found beetles (Burbano-Yandi et al., 2018) and spiders (Poo et al., 2017) consume amphibian eggs, with other studies demonstrating the severe threat of ant predation on turtle nests (Parris et al., 2002, Holbrook et al., 2019, Erickson and Baccaro, 2016, Buhlmann and Coffman, 2001) and bird clutches (Menezes and Marini, 2017). This study also didn't include situations where animals weren't consumed but were caught in spider webs and subsequently died simply due to being entrapped (Graham, 1997, Duca and Modesto, 2007, Kasambe et al., 2010, Martin and Platt, 2011, Brooks, 2012, Walther, 2016). Both situations may remove a considerable number of individuals from a population.

This study demonstrates and further repeats the original assumption of Mccormick and Polis (1982) nearly half a century ago, with arthropod predation and their impact on vertebrate communities remaining underestimated and underappreciated. However, understanding these relationships is even more vital in recent years, especially for vulnerable groups with small populations such as amphibians, of which nearly 40 percent of species are threatened (Díaz et al., 2019). Evidence from conservation management projects has already been demonstrated that arthropod predators can have a major impact on the success of conservation efforts (Valdez, 2019, Feher, 2019). It is therefore vital for future studies to investigate and quantify the effects of arthropod predators on food webs and vertebrate communities within habitats and ecosystems. Although a small number of studies have quantified possible effects, they have occurred under small laboratory settings (Pearman, 1995, Cabrera-Guzmán et al., 2012) or involved clay models (Nordberg et al., 2018). However, new methodologies and technological advances can help quantify arthropod predation, such as camera traps (Hobbs and Brehme, 2017), sentinel prey 
(Lövei and Ferrante, 2017), prey baits, and gut analyses (Birkhofer et al., 2017). Recognizing and quantifying these interactions will fill the gap of knowledge remaining in our ecological understanding. This will help to not only understand the role arthropods predators play in shaping vertebrate communities, but also improve the success of conservation efforts by accounting for predators which may currently be overlooked in threat abatement plans.

\section{Acknowledgments}

I wish to thank John Gould for his inspiration and time providing valuable feedback.

\section{References}

Abbott, C. G. 1931. Birds caught in spiders' webs. The Condor, 33, 169-169.

Babangenge, G. B., Jocqué, R., Masudi, F. M., Rödel, M.-O., Burger, M., Gvoždík, V. \& Pauwels, O. S. 2019. Frog-eating Spiders in the Afrotropics: An Analysis of Published and New Cases. Bulletin of the Chicago Herpetological Society, 54, 57-63.

Bastos, R., Oliveira, O. \& Pombal Jr, J. 1994. Hyla minuta. Predation. Herpetological Review, 25, 118.

Bernarde, P., Souza, M. D. \& Kokubum, M. 1999. Predation on Hyla minuta Peters, 1872 (Anura, Hylidae) by Ancylometes spp.(Araneae, Pisauridae). Biociências, 7, 199-203.

Beschta, R. L. \& Ripple, W. J. 2009. Large predators and trophic cascades in terrestrial ecosystems of the western United States. Biological Conservation, 142, 2401-2414. https://doi.org/10.1016/j.biocon.2009.06.015

Birkhofer, K., Bylund, H., Dalin, P., Ferlian, O., Gagic, V., Hambäck, P. A., Klapwijk, M., Mestre, L., Roubinet, E., Schroeder, M., Stenberg, J. A., Porcel, M., Björkman, C. \& Jonsson, M. 2017. Methods to identify the prey of invertebrate predators in terrestrial field studies. Ecology and Evolution, 7, 1942-1953. 10.1002/ece3.2791

Blondheim, S. \& Werner, Y. 1989. Lizard predation by the widow spiders Latrodectus pallidus and L. revivensis (Theridiidae). British Herpetological Society Bulletin, 30, 26-27.

Brooks, D. M. 2012. Birds caught in spider webs: a synthesis of patterns. The Wilson Journal of Ornithology, 124, 345-353.

Buhlmann, K. A. \& Coffman, G. 2001. Fire ant predation of turtle nests and implications for the strategy of delayed emergence. Journal of the Elisha Mitchell Scientific Society, 117, 94100.

Burbano-Yandi, C. E., Loaiza-Piedrahita, J. D. \& Arenas-Clavijo, A. 2018. Predation of glass frog (Anura: Centrolenidae) eggs by a ground beetle (Coleoptera: Carabidae) in Colombia. Phyllomedusa: Journal of Herpetology, 17, 131-134.

Butler, W. \& Main, B. 1959. Predation on vertebrates by mygalomorph spiders. Western Australian Naturalist, 7, 52.

Cabrera-Guzmán, E., Crossland, M. R. \& Shine, R. 2012. Predation on the eggs and larvae of invasive cane toads (Rhinella marina) by native aquatic invertebrates in tropical Australia. Biological Conservation, 153, 1-9. https://doi.org/10.1016/j.biocon.2012.04.012

Darwin, C. 1859. On the origin of species, Routledge. 
De Armas, L. F. 2001. Frogs and lizards as prey of some Greater Antillean arachnids. Revista ibérica de aracnología, 3, 87-88.

Díaz, S., Settele, J., Brondízio, E., Ngo, H. T., Guèze, M., Agard, J., Arneth, A., Balvanera, P., Brauman, K., Butchart, S., Chan, K., Garibaldi, L., Ichii, K., Liu, J., Subramanian, S. M., Midgley, G., Miloslavich, P., Molnár, Z., Obura, D., Pfaff, A., Polasky, S., Purvis, A., Razzaque, J., Reyers, B., Chowdhury, R. R., Shin, Y.-J., Hamakers, I. V., Willis, K. \& Zayas, C. Summary for policymakers of the global assessment report on biodiversity and ecosystem services of the Intergovernmental Science-Policy Platform on Biodiversity and Ecosystem Services. In: Carneiro da Cunha, M., Mace, G. \& Mooney, H., eds. IPBES-7th Plenary, 6 May 20192019 Paris, France. Intergovernmental Science-Policy Platform on Biodiversity and Ecosystem Services.

Duca, C. \& Modesto, W. 2007. Spider web as a natural trap for small birds. Rev Bras Ornitol, 15, 615-616.

Duellman, W. E. \& Trueb, L. 1994. Biology of amphibians, JHU press.

Erickson, J. \& Baccaro, F. 2016. Nest predation of the yellow-spotted Amazon River turtle (Podocnemis unifilis, Troschel, 1848) by the fire ant (Solenopsis geminata, Fabricius, 1804) in the Brazilian Amazon. The Herpetological Journal, 26, 183-186.

Estes, J. A., Terborgh, J., Brashares, J. S., Power, M. E., Berger, J., Bond, W. J., Carpenter, S. R., Essington, T. E., Holt, R. D., Jackson, J. B. C., Marquis, R. J., Oksanen, L., Oksanen, T., Paine, R. T., Pikitch, E. K., Ripple, W. J., Sandin, S. A., Scheffer, M., Schoener, T. W., Shurin, J. B., Sinclair, A. R. E., Soulé, M. E., Virtanen, R. \& Wardle, D. A. 2011. Trophic Downgrading of Planet Earth. Science, 333, 301-306. 10.1126/science.1205106

Fadel, R. M., Thaler, R., Folly, H., Galvão, C., Hoffmann, M., Da Silva, L. A., Santana, D. J. \& Mângia, S. 2019. Predation of anurans across multiple life stages in an Amazon-Cerrado transitional zone. Herpetology Notes, 12, 895-899.

Feher, K. 2019. Winter dynamics in mountain lakes and impacts of an introduced species to the endangered Devils Hole pupfish. M.Sc., University of Nevada, Reno.

Fisher Jr, R. 1994. Praying mantis catches and eats hummingbird. Birding, 26, 376.

Froese, R. \& D., P. 2019. FishBase

Garb, J. E. \& Hayashi, C. Y. 2013. Molecular evolution of $\alpha$-latrotoxin, the exceptionally potent vertebrate neurotoxin in black widow spider venom. Molecular biology and evolution, 30, 999-1014.

Gould, J., Valdez, J. W., Clulow, J. \& Clulow, S. 2019. Diving beetle offspring oviposited in amphibian spawn prey on the tadpoles upon hatching. Entomological Science, 22, 393-397. 10.1111/ens. 12381

Graham, D. L. 1997. Spider Webs and Windows as Potentially Important Sources of Hummingbird Mortality (Telas de Araña y Ventanas Como Fuentes Potenciales de Mortalidad para Zumbadores). Journal of Field Ornithology, 68, 98-101.

Greene, H. W. 1997. Snakes: the evolution of mystery in nature, Univ of California Press.

Gregio, A., Heleno, M., Von Eicksted, V. \& Fontana, M. 1999. The neuromuscular action of Ancylometes sp. spider venom in the rat phrenic nerve-diaphragm preparation. Toxicon, 37, 545-550.

Gross, H. P. 1978. Natural selection by predators on the defensive apparatus of the three-spined stickleback, Gasterosteus aculeatus L. Canadian Journal of Zoology, 56, 398-413.

Hibbitts, T. 1992. Hypsiglena torquata (night snake). Predation. Herpetological Review, 23, 120.

Hildebrand, E. M. 1949. Hummingbird captured by preying mantis. The Auk, 66, 286-286. 
Hobbs, M. T. \& Brehme, C. S. 2017. An improved camera trap for amphibians, reptiles, small mammals, and large invertebrates. PLOS ONE, 12, e0185026. 10.1371/journal.pone.0185026

Holbrook, C. T., Mahas, J. W., Ondich, B. L. \& Andrews, K. M. 2019. The Threat of Predatory Fire Ants to Loggerhead Turtles Nesting on Jekyll Island, Georgia, USA. Marine Turtle Newsletter, 156, 5-9.

Kasambe, R., Thosar, G., Rathore, H., Shivkar, A. \& Sasi, D. 2010. Recent records of birds trapped in spiders' webs in India. BirdingASIA, 13, 82-4.

Kenis, M., Hurley, B. P., Hajek, A. E. \& Cock, M. J. W. 2017. Classical biological control of insect pests of trees: facts and figures. Biological Invasions, 19, 3401-3417. 10.1007/s10530-017-1414-4

Kopp, K., Wachlevski, M. \& Eterovick, P. C. 2006. Environmental complexity reduces tadpole predation by water bugs. Canadian Journal of Zoology, 84, 136-140. 10.1139/z05-186

Kuntner, M. \& Agnarsson, I. 2010. Web gigantism in Darwin's bark spider, a new species from Madagascar (Araneidae: Caerostris). The Journal of Arachnology, 38, 346-356, 11.

Leong, M., Bertone, M. A., Savage, A. M., Bayless, K. M., Dunn, R. R. \& Trautwein, M. D. 2017. The Habitats Humans Provide: Factors affecting the diversity and composition of arthropods in houses. Scientific reports, 7, 15347-15347. 10.1038/s41598-017-15584-2

Lever, C. 2001. The cane toad: the history and ecology of a successful colonist, Westbury Academic \& Scientific Pub.

Lorenz, S. 2007. Carolina mantid (Stagmomantis carolina) captures and feeds on a Broad-tailed Hummingbird (Selasphorus platycercus). Bulletin of the Texas Ornithological Society, 40, 37-38.

Lövei, G. L. \& Ferrante, M. 2017. A review of the sentinel prey method as a way of quantifying invertebrate predation under field conditions. Insect Science, 24, 528-542. 10.1111/17447917.12405

Maffei, F., Ubaid, F. K. \& Jim, J. 2010. Predation of herps by spiders (Araneae) in the Brazilian Cerrado. Herpetology Notes, 3, 167-170.

Martin, J. \& Platt, S. G. 2011. Mortality of a Black-chinned Hummingbird following entanglement in a spider web. Bulletin of the Texas Ornithological Society, 44, 95-96.

Mccormick, S. \& Polis, G. A. 1982. Arthropods that prey on vertebrates. Biological Reviews, 57, 29-58.

Ménez, A., Zimmerman, K., Zimmerman Ms, S. \& Heatwole, H. 1990. Venom apparatus and toxicity of the centipede Ethmostigmus rubripes (Chilopoda, Scolopendridae). Journal of Morphology, 206, 303-312. 10.1002/jmor.1052060307

Menezes, J. C. T. \& Marini, M. Â. 2017. Predators of bird nests in the Neotropics: a review. Journal of Field Ornithology, 88, 99-114. 10.1111/jofo.12203

Menin, M., De Jesus Rodrigues, D. \& De Azevedo, C. S. 2005. Predation on amphibians by spiders (Arachnida, Araneae) in the Neotropical region. Phyllomedusa: Journal of Herpetology, 4, 39-47.

Moran, M. D. \& Hurd, L. E. 1997. A trophic cascade in a diverse arthropod community caused by a generalist arthropod predator. Oecologia, 113, 126-132. 10.1007/s004420050360

Moran, M. D., Rooney, T. P. \& Hurd, L. E. 1996. Top-Down Cascade from a Bitrophic Predator in an Old-Field Community. Ecology, 77, 2219-2227. 10.2307/2265715

Morris, B. 1963. Bird-eating spiders. African Wildlife, 17, 343. 
Murray, J. 1958. Ruby-throated Hummingbird captured by a praying mantis. The Wilson Bulletin, 70, 381-381.

Neill, W. T. 1948. Spiders preying on reptiles and amphibians. Herpetologica, 4, 158-158.

Nordberg, E. J., Edwards, L. \& Schwarzkopf, L. 2018. Terrestrial invertebrates: An underestimated predator guild for small vertebrate groups. Food Webs, 15, e00080. https://doi.org/10.1016/j.fooweb.2018.e00080

Nyffeler, M. \& Birkhofer, K. 2017. An estimated 400-800 million tons of prey are annually killed by the global spider community. The Science of Nature, 104, 30. 10.1007/s00114-0171440-1

Nyffeler, M., Edwards, G. \& Krysko, K. L. 2017a. A vertebrate-eating jumping spider (Araneae: Salticidae) from Florida, USA. The Journal of Arachnology, 45, 238-242.

Nyffeler, M. \& Knörnschild, M. 2013. Bat predation by spiders. PloS one, 8, e58120.

Nyffeler, M., Maxwell, M. R. \& Jr., J. V. R. 2017b. Bird Predation By Praying Mantises: A Global Perspective. The Wilson Journal of Ornithology, 129, 331-344, 14.

Nyffeler, M. \& Pusey, B. J. 2014. Fish predation by semi-aquatic spiders: a global pattern. PloS one, 9, e99459.

Nyffeler, M. \& Vetter, R. S. 2018. Black widow spiders, Latrodectus spp.(Araneae: Theridiidae), and other spiders feeding on mammals. The Journal of Arachnology, 46, 541-549.

O'shea, M. \& Kelly, K. 2017. Predation on a Weasel Skink (Saproscincus mustelinus)(Squamata: Scincidae: Lygosominae) by a Redback Spider (Latrodectus hasselti)(Araneae: Araneomorpha: Theridiidae), with a review of other Latrodectus predation events involving squamates. Herpetofauna, 44, 49-55.

Ohba, S.-Y. 2019. Ecology of giant water bugs (Hemiptera: Heteroptera: Belostomatidae). Entomological Science, 22, 6-20. 10.1111/ens.12334

Parris, L. B., Lamont, M. M. \& Carthy, R. R. 2002. Increased incidence of red imported fire ant (Hymenoptera: Formicidae) presence in loggerhead sea turtle (Testudines: Cheloniidae) nests and observations of hatchling mortality. Florida Entomologist, 85, 514-518.

Pearman, P. B. 1995. Effects of Pond Size and Consequent Predator Density on Two Species of Tadpoles. Oecologia, 102, 1-8.

Poo, S., Erickson, F. T., Mason, S. A. \& Nissen, B. D. 2017. Predation of Feihyla hansenae (Hansen's bush frog) eggs by a nursery web spider. Herpetological Bulletin, 139, 36-37.

Portalier, S. M. J., Fussmann, G. F., Loreau, M. \& Cherif, M. 2019. The mechanics of predatorprey interactions: First principles of physics predict predator-prey size ratios. Functional Ecology, 33, 323-334. 10.1111/1365-2435.13254

Ripple, W. J. \& Beschta, R. L. 2012. Trophic cascades in Yellowstone: The first 15 years after wolf reintroduction. Biological Conservation, 145, 205-213. https://doi.org/10.1016/j.biocon.2011.11.005

Rivera, J. \& Callohuari, Y. 2019. A New Species of Praying Mantis from Peru Reveals Impaling as a Novel Hunting Strategy in Mantodea (Thespidae: Thespini). Neotropical Entomology. 10.1007/s13744-019-00744-y

Sergio, F., Newton, I. \& Marchesi, L. 2005. Conservation: top predators and biodiversity. Nature, 436, 192.

Sergio, F., Newton, I., Marchesi, L. \& Pedrini, P. 2006. Ecologically justified charisma: preservation of top predators delivers biodiversity conservation. Journal of Applied Ecology, 43, 1049-1055. 
Stanton, M., Feuerbacher, O. \& Gumm, J. Beetle-Mania: Management of a Native Predator in a Refuge Ecosystem. American Fisheries Society \& The Wildlife Society 2019 Joint Annual Conference, 2019. AFS.

Steehouder, T. 1992. Spiders as herpeto-eaters. Litteratura Serpentium, 12, 71.

Terborgh, J. \& Estes, J. A. 2013. Trophic cascades: predators, prey, and the changing dynamics of nature, Island Press.

Tewksbury, J. J., Anderson, J. G. T., Bakker, J. D., Billo, T. J., Dunwiddie, P. W., Groom, M. J., Hampton, S. E., Herman, S. G., Levey, D. J., Machnicki, N. J., Del Rio, C. M., Power, M. E., Rowell, K., Salomon, A. K., Stacey, L., Trombulak, S. C. \& Wheeler, T. A. 2014. Natural History's Place in Science and Society. BioScience, 64, 300-310. 10.1093/biosci/biu032

Toledo, L. F. 2005. Predation of juvenile and adult anurans by invertebrates: current knowledge and perspectives. Herpetological Review, 36, 395-399.

Valdez, J. W. 2019. Predaceous diving beetles (Coleoptera : Dytiscidae) may affect the success of amphibian conservation efforts. Australian Journal of Zoology, 66, 352-355. 10.1071/zo19039

Walther, B. A. 2016. Birds caught in spider webs in Asia. Avian Research, 7, 16.

Wizen, G. \& Gasith, A. 2011. An unprecedented role reversal: ground beetle larvae (Coleoptera: Carabidae) lure amphibians and prey upon them. PloS one, 6, e25161. 